\title{
Effect of PVP Intermediate Layer on the Properties of SAPO 34 Membrane
}

\author{
Jugal K. Das, Nandini Das, and Sibdas Bandyopadhyay \\ Ceramic Membrane Division, Central Glass and Ceramic Research Institute, CSIR, Jadavpur, Kolkata 700 032, India \\ Correspondence should be addressed to Nandini Das, nandinid100@rediffmail.com
}

Received 30 September 2011; Accepted 5 December 2011

Academic Editor: Chang-An Wang

Copyright ( 2012 Jugal K. Das et al. This is an open access article distributed under the Creative Commons Attribution License, which permits unrestricted use, distribution, and reproduction in any medium, provided the original work is properly cited.

SAPO 34 zeolite membranes were prepared on a tubular mullite support. Before membrane preparation, the support surfaces were coated with seed crystals. Seeds particles were prepared by hydrothermal synthesis. Before seeding, the substrates were treated with polyvinylpyrrolidone (PVP) to orient the seeds. Both the treated and untreated supports were seeded, and membranes were synthesized on those support tubes by ex situ hydrothermal method. The PVP molecule exists in the two resonance structures. Hence the acylamino bond $-\mathrm{N}^{+}=\mathrm{C}-\mathrm{O}^{-}-$acts as intermediate linker between support surface and seed surface. Due to charge interaction, the seed crystals were anchored strongly to support surface. The synthesized membranes along with seed crystals were characterized by XRD, FESEM, and EDAX analysis. The single-gas permeation with $\mathrm{CO}_{2}$ and $\mathrm{H}_{2}$ was investigated. Up to 5 bar of feed pressure, the permselectivity of $\mathrm{CO}_{2}$ and $\mathrm{H}_{2}$ was as high as 4.2.

\section{Introduction}

Hydrogen is being considered as the most clean, reliable, environmentally benign and affordable future energy source [1-3]. Hydrogen can be produced by various routes such as biomass, water, coal, natural gas, nuclear power, renewable energies, and wastes [4]. To apply hydrogen as fuels and chemicals, transport and power energy source, we have to separate hydrogen from carbonaceous gas. Because $\mathrm{CO}_{2}$ reduces the energy content of the gas, and it is acidic and corrosive in presence of water within the transport and storage system [5]. The traditional cryogenic distillation, adsorbent bed processes, and pressure swing methods are used for gas separation in many industries. But in recent times, however, membrane-based gas separation is becoming increasingly popular due to its inherent advantage over the more traditional method. These include low capital and operating cost, lower energy requirement, and generally ease of operation.

Silicoaluminophosphate (SAPO 34) with chabazite(CHA-) type frame work having pore diameter $0.38 \mathrm{~nm}$ is an efficient member of zeolite family, has been studied for various applications, and, most notably, has shown excellent performance in separations, catalysis, and adsorption [6-11].
Considering their molecular sieving properties and uniform pore size, high thermal resistance, high mechanical strength, and order microporous structure, zeolite membrane have attracted great interest and successfully employed to separate carbon dioxide and hydrogen from different gases [12-15]. This small-pore SAPO 34 zeolite membrane has good $\mathrm{H}_{2} / \mathrm{CO}_{2}$ permeation ability due to a combination of difference in diffusivity and competitive adsorption. There are many reports on the improvement of the formation stages of the membranes like microwave heating $[16,17]$, addition of intermediate silane layer to increase the adhesion between gel layer and supporting substrate [18], vacuum seeding [19], and so forth. The in situ hydrothermal synthesis appears to be the best studied method, in which the porous support is immersed into the synthesis solution, and then the membrane is formed by direct crystallization. However, it is difficult to prepare high-quality membrane by this in situ crystallization method directly [20]. Coating the zeolite seed on the support surface before hydrothermal synthesis, which is also termed as secondary growth method, is an effective approach to develop a high-quality zeolite membrane. It is well known that the presence of seed on the support surface plays a vital role in membrane formation. Synthesis with seeds gives a better control of the membrane formation 


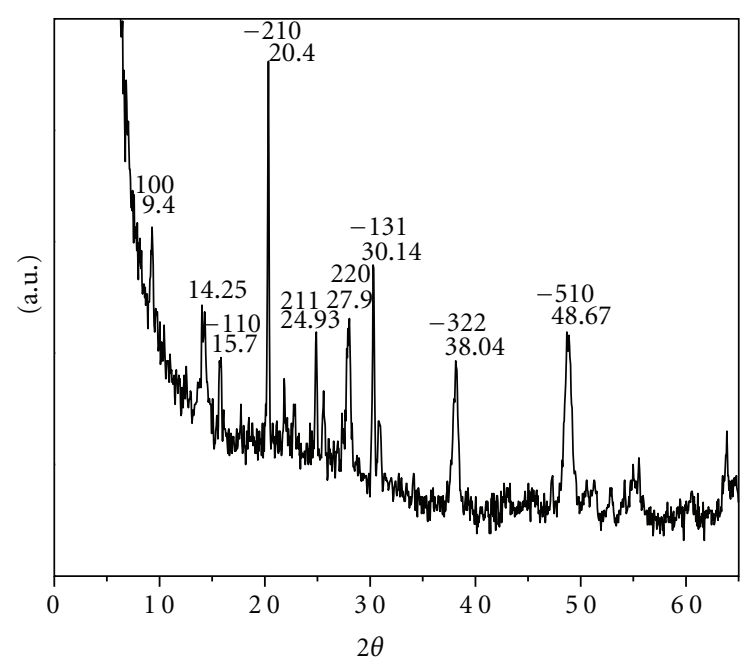

(a)

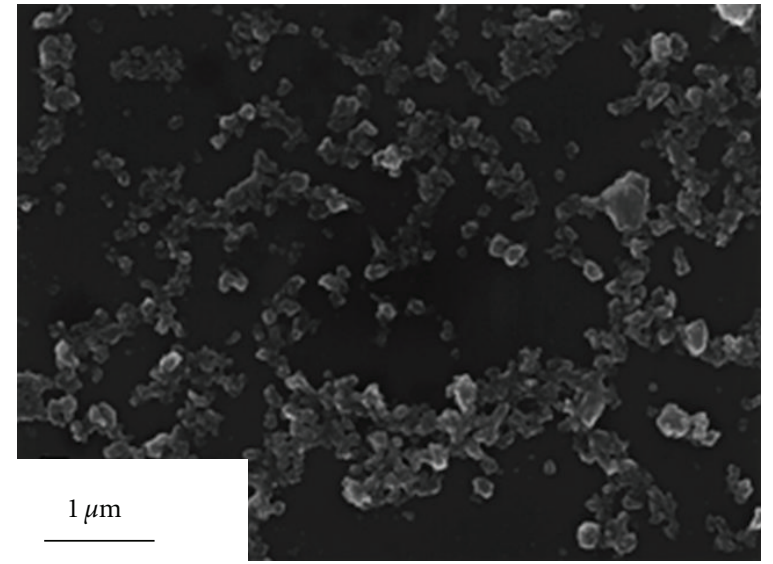

(b)

Figure 1: (a) XRD pattern and (b) FESEM of SAPO 34 crystals used as seed for membrane synthesis.

process by separating the crystal nucleation and growth with a shortened crystallization time [21]. In addition, the secondary growth ensures the formation of the phase pure zeolite crystal on the support. The secondary growth method which was proposed by Lovallo and Tsapatsis [22] exhibits many advantages such as better control over membrane microstructure and higher reproducibility [23].

An important approach to the preparation of SAPO 34 zeolite monolayer with solid packing was binding zeolite crystals to the support substrate through a molecular linker by covalent bonding, ionic linkage, and hydrogen bonding [24-26]. Molecular linkers are nothing but the intermediate buffer layer of high importance in the fabrication of a uniformly oriented zeolite monolayer as they can bind and form homogeneous closely packed membrane layer on the support.

In this work, we report a simple technique for proper orientation of SAPO 34 seed crystals on support surface to synthesize a SAPO 34 zeolite membrane layer on clay alumina substrate by secondary growth method. Almostdense zeolite membrane was synthesized on properly seeded substrate. The ultimate performance of the membrane was characterized by gas permeation studies.

\section{Experimental}

\subsection{Membrane Synthesis}

2.1.1. Seeds Synthesis. The materials used for the synthesis were boehmite powder (SASOL), silica sol (Ludox 40 AS), phosphoric acid (Qualigens Fine Chemicals, India), and morpholine (SD fine chemicals, India), as well as distilled water. Two reactant mixtures were prepared, respectively, dissolving boehmite powder, phosphoric acid, and required amount of water (mixture 1) to the reaction mixture. The mixture was stirred for overnight. In another mixture (mixture 2), silica sol and morpholine were added, and the remaining amount of water was added to the reaction mixture. After stirring mixture 2 for $1 \mathrm{~h}$, it was mixed slowly under stirring at room temperature with mixture 1. The resulting mixture was stirred vigorously for 15$30 \mathrm{~min}$ and kept under stirring for overnight to produce a homogeneous sol. The molar composition of the sol used for the synthesis was $\mathrm{Al}_{2} \mathrm{O}_{3}: \mathrm{SiO}_{2}: \mathrm{P}_{2} \mathrm{O}_{5}: \mathrm{H}_{2} \mathrm{O} 1: 0.3: 1: 66$. The prepared homogeneous sol was kept in a Teflon line hydrothermal bomb and heated at $170^{\circ} \mathrm{C}$ for $120 \mathrm{~h}$. At the end of synthesis, the seeds were centrifuged at $12000 \mathrm{rpm}$ for $20 \mathrm{~min}$ and washed with distilled water. The procedure was repeated 4 times. The resultant precipitate was dried overnight and calcined at $100^{\circ} \mathrm{C}$ for $1 \mathrm{~h}$.

2.1.2. Seeding of the Substrate. SAPO 34 seed crystals were dispersed in deionised water under ultrasonication for $2 \mathrm{~h}$. Indigenous mullite tube of diameter $10 \mathrm{~mm}$ and thickness $3 \mathrm{~mm}$ and $60 \mathrm{~mm}$ length was used as substrate for synthesis of SAPO-34 membranes. Before seeding, the substrates were cleaned with acetone in an ultrasonic cleaner (Vibracell, USA) for 5 minutes. The outer surface of the support tubes was wrapped with Teflon sheet so that the zeolite layer was formed inside the tube. Before addition of seed crystals, the support substrate was coated with 3\% aqueous solution of PVP. To increase the orientation of the seed crystals on support surface, an intermediate PVP layer was applied. The treated and untreated support substrate was dipped in a 3\% SAPO 34 zeolite suspension in deionized water 5 times for duration of $15 \mathrm{~s}$. After the dipping procedure, the seeded supports were dried at $80^{\circ} \mathrm{C}$ for $24 \mathrm{~h}$.

2.1.3. SAPO-34 Membrane Synthesis. The seeded substrate was placed vertically in an autoclave. The autoclave was filled with reaction mixture having composition $\mathrm{Al}_{2} \mathrm{O}_{3}: \mathrm{SiO}_{2}$ : $\mathrm{P}_{2} \mathrm{O}_{5}: \mathrm{H}_{2} \mathrm{O} 1: 0.3: 1: 66$. The procedure was same as seed synthesis. The synthesized membranes were calcined in air at $550^{\circ} \mathrm{C}$ for $5 \mathrm{~h}$ to remove the templates. 


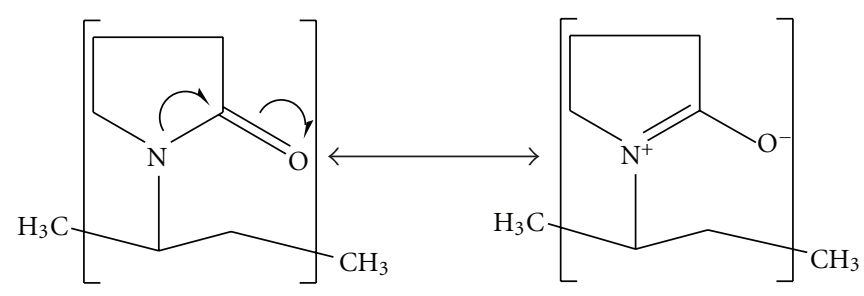

(a)

(b)

FIGURE 2: Schematic of the resonance structures of PVP molecule.
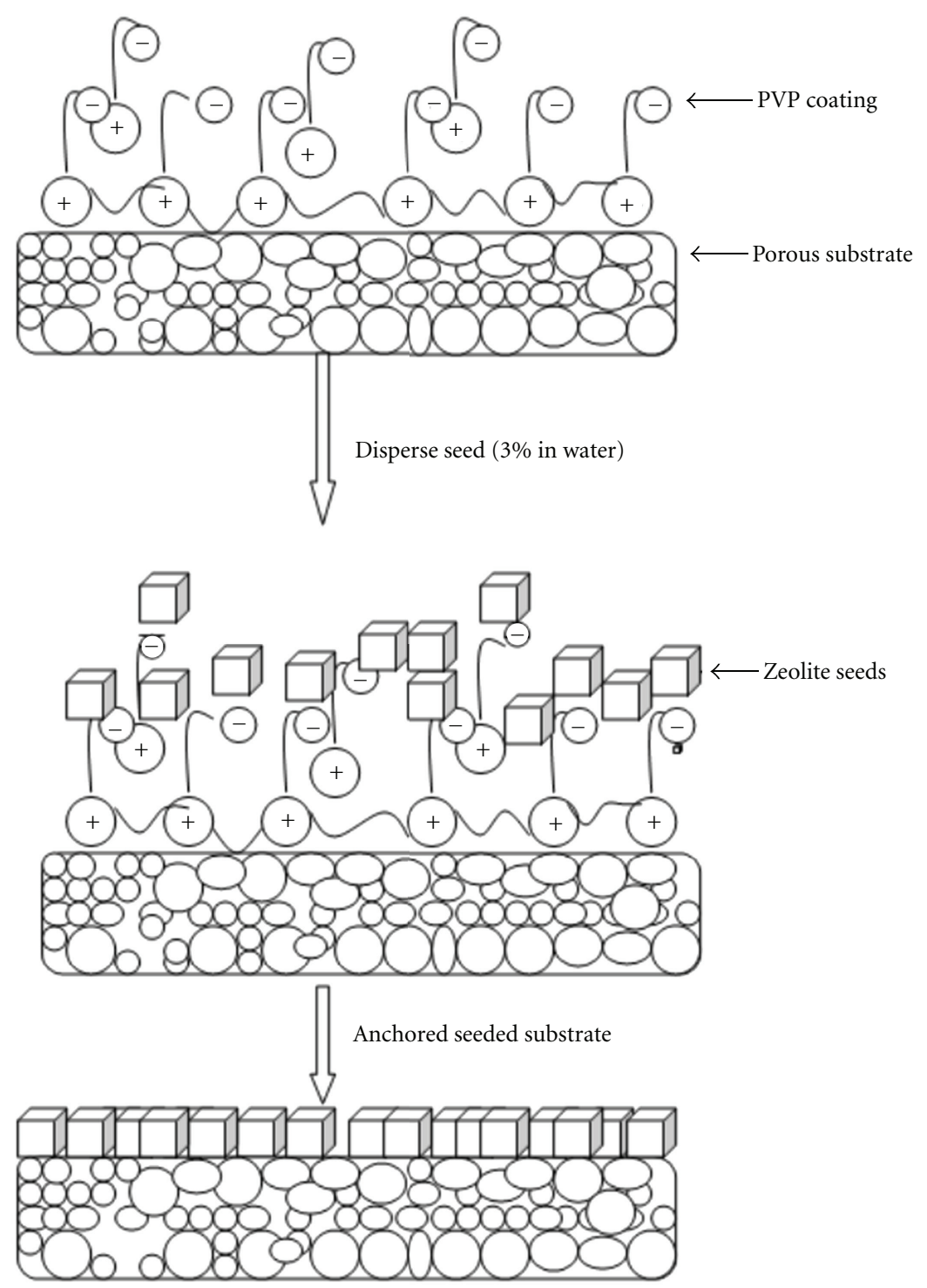

FIGURE 3: Schematic representation of seeded membrane with PVP intermediate layer.

2.2. Membrane Characterization. The crystalline structure of the as-synthesized membrane was determined by XRD pattern. XRD was carried out on a Philips 1710 diffractometer using $\mathrm{CuK}_{\alpha}$ radiation $(\alpha=1.541 \AA)$.

Microstructure and morphology of the growth layer were examined using scanning electron microscopy (FESEM: model Leo, S430i, UK).
Single-gas permeation for $\mathrm{H}_{2}$ and $\mathrm{CO}_{2}$ was measured by a specially designed permeation cell developed in our laboratory. The gas permeance of the membranes was measured by soap film flow meter under the feed pressure of 2 to $5 \mathrm{~kg} / \mathrm{cm}^{2}$ and at room temperature. The permselectivity of two gases $G_{1} / G_{2}$ was defined as the permeance ratio of $G_{1}$ and gas $\mathrm{G}_{2}$. The gas permeation measurement of each single gas was 
repeated until the permeance data for the successive 10 tests were closed.

\section{Results and Discussion}

Figure 1(a) depicts the XRD pattern of SAPO 34 seeds crystals prepared by hydrothermal technique at $170^{\circ} \mathrm{C}$ for $120 \mathrm{~h}$. The characteristics of the peaks of seed crystals are designed by their (hkl) values. The morphology of those SAPO 34 crystals is shown in Figure 1(b). Comparing the $\mathrm{XRD}$ and FESEM, the size range of seed crystals is $100 \mathrm{~nm}$. The surface area of the synthesized powder was $660 \mathrm{~m}^{2} / \mathrm{g}$. In order to form a continuous zeolite membrane on support surface, the coverage of the seed crystals must be high. For higher coverage, smaller-sized seed crystals are most suitable. According to the formation mechanism of zeolite membrane on the porous support, the nucleation of zeolite on the support gel interface and that in the bulk synthesis mixture are competitive processes. Thus to develop a continuous membrane layer, the nucleation of zeolite in the bulk synthesis mixture must be inhibited, while the nucleation of zeolite on the support surface must be increased. Another advantage of surface seeding for preparation of membrane layer on support surface is formation of zeolite phase is accelerated. Polycrystalline zeolite membrane contains defects, that is, inter-crystalline pathway which is also called non-zeolitic pores. The transport mechanism of gas molecules through non-zeolitic pores is difficult, and it is difficult to quantify, because the pore size of these nonzeolitic pores is not well defined. Usually non-zeolitic pores are larger than zeolitic pores. Presence of non-zeolitic pores reduces the selectivity of the gases. The main sources of non zeolitic pores result from cracks and defects of the membrane layer. The main cause of the crack is due to the lack of good adherence between zeolite layer and substrate layer. Considering this fact and to obtain a crack-free membrane layer on the substrate, proper seeding on the surface is desirable. In our previous work [27], we have reported that application of intermediate layer between substrate and seed reduces the defects. The PVP molecule exits in the two resonance structures. In case of PVP, the oxygen atom is more electronegative than nitrogen atom, and it is expected that negative charge on PVP prefers to reside on oxygen atom. Figure 2 shows resonance structure of the PVP molecule. The partial positive charge nitrogen atom and partial negative charge on the oxygen atom can behave as electron acceptor and, donor respectively. Hence the acylamino bond $-\mathrm{N}^{+}=$ $\mathrm{C}-\mathrm{O}^{-}-$acts as intermediate linker between support surface and seed surface. Due to charge interaction, the seed crystals were anchored strongly to support surface. Figure 3 depicts the schematic representation of anchoring between support surface and seed crystals. The seeded supports were hydrothermally treated at $170^{\circ} \mathrm{C}$ from $48 \mathrm{~h}$ to $120 \mathrm{~h}$. Figure 4 shows the XRD pattern of SAPO 34 membrane synthesized for $48 \mathrm{~h}, 72 \mathrm{~h}, 96 \mathrm{~h}$, and $120 \mathrm{~h}$ and compared with standard pattern of SAPO 34 zeolite. As the diffraction intensity of the SAPO 34 zeolite membrane on support surface was too weak to detect by XRD, the diffraction pattern of the bulk powders collected from hydrothermal container was

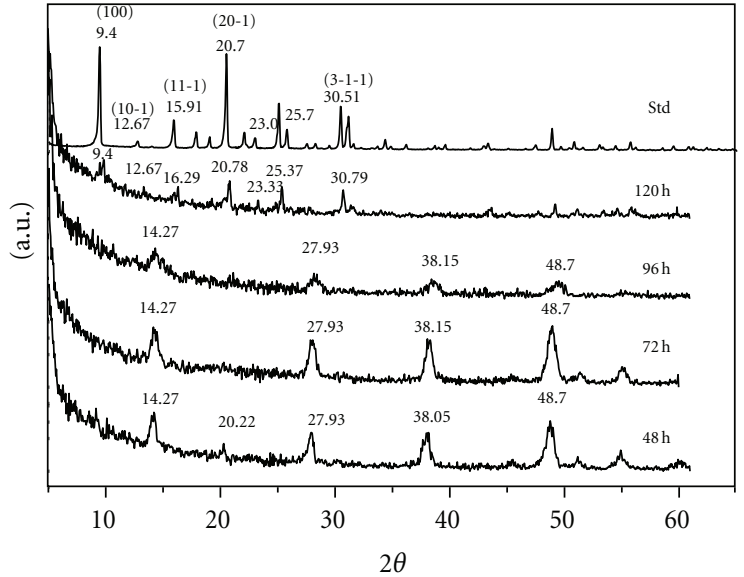

FIGURE 4: XRD pattern of SAPO 34 crystals synthesized for different time ranging from $48 \mathrm{~h}$ to $120 \mathrm{~h}$.

studied. It is clear from the XRD pattern that after $48 \mathrm{~h}$ of synthesis some crystalline phase started to form and continued up to $72 \mathrm{~h}$, but the phase was not SAPO 34 . After prolonged heating, at $96 \mathrm{~h}$, the crystalline phase was converted into amorphous phase, and on further heating, it was transformed into SAPO 34 after $120 \mathrm{~h}$. Figures 5(a) and 5(b) show the FESEM images of membrane synthesized at $120 \mathrm{~h}$ with properly seeded support surface. To ensure the proper formation of membrane layer on support substrate and uniform distribution of component elements, the elemental mapping along with EDAX analysis of the SAPO 34 membrane was studied. Figure 6(a) shows the corresponding membrane layers with homogeneous interlocked structure. Elemental mapping (Figures 6(b)-6(e)) and EDAX analysis (Figure 6(f)) confirm the formation of SAPO 34 membrane layer. The quantitative elemental analysis of the synthesized SAPO 34 as membrane coating is described in table, inside the spectral figure. However XRD and FESEM can only indicate whether a continuous membrane was formed or not on the support, but cannot confirm the quality of zeolite membrane. The quality of zeolite membrane can only be evaluated by gas permeation properties of the membrane. It is well known that performance of a membrane will increase with decreasing defects.

The permeation of $\mathrm{CO}_{2}$ and $\mathrm{H}_{2}$ were measured at room temperature directly after calcining the membrane. The permeation of gas through the micropores of the zeolite can be explained quantitatively by adsorption-diffusion mechanism, where the permeated flux is expressed as the diffusion rate through the micropores between the two sides of the membrane. The diffusion rate becomes significantly smaller where the kinetic diameter of the gas becomes larger than the size of the zeolitic pores due to the molecular sieving effect. The molecular kinetic diameters of $\mathrm{H}_{2}$ and $\mathrm{CO}_{2}$ are 0.29 and $0.33 \mathrm{~nm}$, respectively, which are close to the pore size of SAPO 34 zeolite. The configurational diffusion and the difference in molecular size between $\mathrm{H}_{2}$ and $\mathrm{CO}_{2}$ result in the difference in the rate of diffusion through the SAPO 34 zeolite channels. The diffusion rate of $\mathrm{H}_{2}$ is faster than 


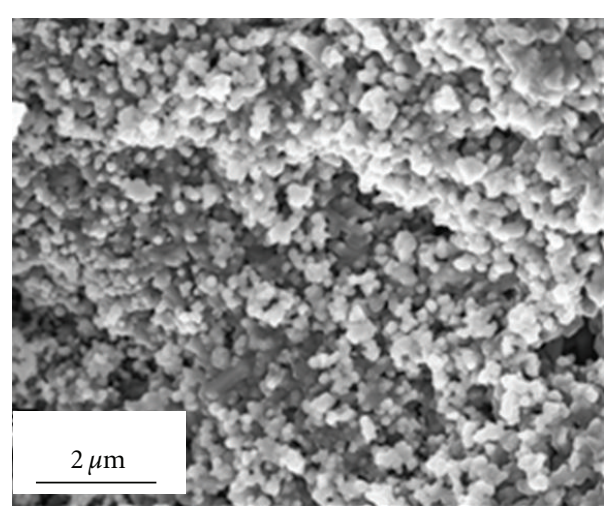

(a)

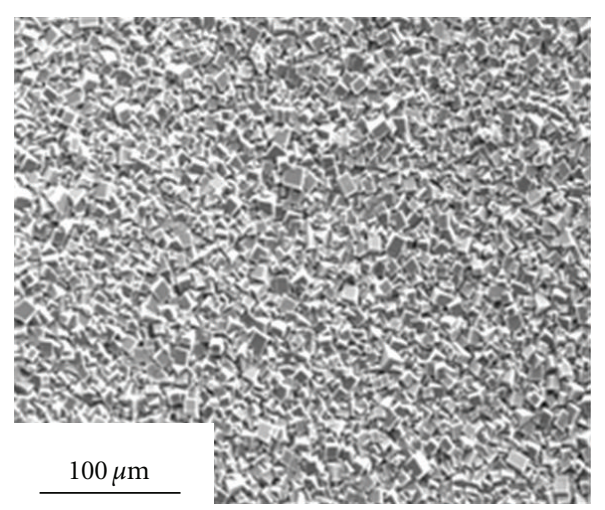

(b)

FIGURE 5: FESEM micrograph of (a) substrate with PVP intermediate layer with seed layer, (b) membrane layer synthesized on seeded substrate.

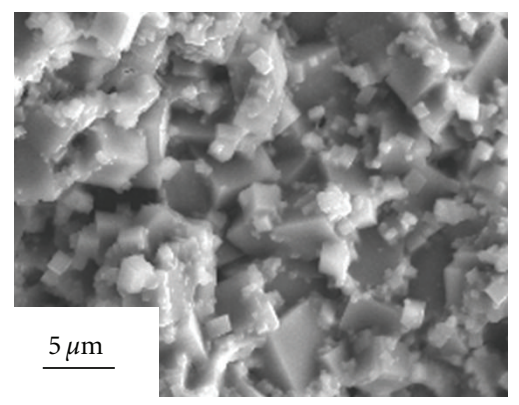

(a)

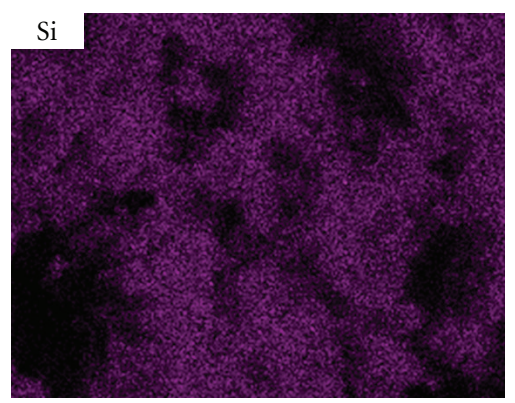

(d)

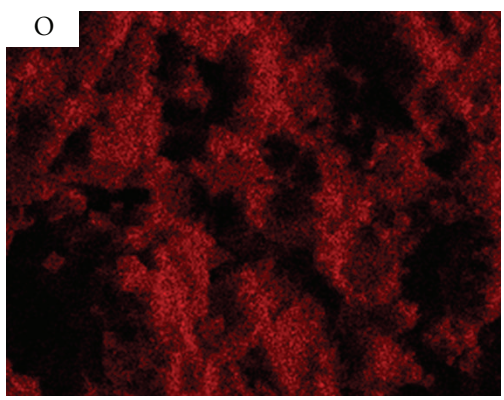

(b)

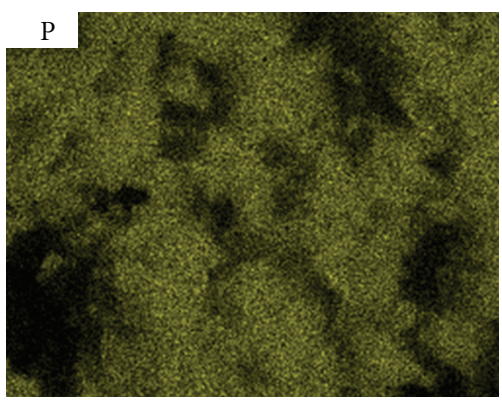

(e)

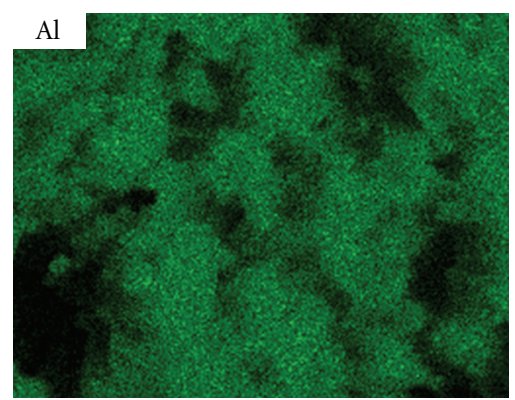

(c)

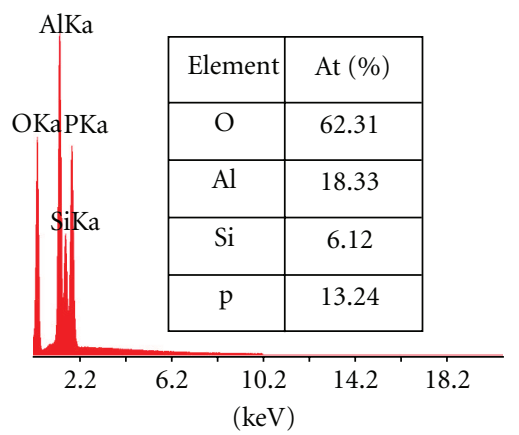

(f)

FIGURE 6: (a) FESEM micrograph of SAPO 34 membrane, and (b-e) represent the elemental mapping $(\mathrm{O}, \mathrm{Al}, \mathrm{Si}$, and P) of the developed membrane and (f) corresponding EDAX spectra of the membrane layer along with atomic percentage.

that of $\mathrm{CO}_{2}$, and therefore, $\mathrm{H}_{2}$ and $\mathrm{CO}_{2}$ can be separated by SAPO 34 zeolite membrane. So the single-gas permeation depends on the kinetic diameter of the gases. Tables 1 and 2 describe the permeability of $\mathrm{CO}_{2}$ and $\mathrm{H}_{2}$ through the SAPO 34 membrane prepared without any intermediate layer and PVP intermediate layer, respectively, before seeding, under different pressure. $\mathrm{CO}_{2}$ has a lower permeance than $\mathrm{H}_{2}$. The rate of change of permeance with pressure is less for $\mathrm{CO}_{2}$ than $\mathrm{H}_{2}$. At high pressure, $\mathrm{CO}_{2}$ is adsorbed more strongly on SAPO 34 zeolite membrane surface than $\mathrm{H}_{2}$, and the rate of desorption of $\mathrm{CO}_{2}$ from the membrane surface also decreased. As a result, flux rate decreases. Therefore, the $\mathrm{H}_{2} / \mathrm{CO}_{2}$ selectivity is changed from 1.16 to 4.2 . Comparison of the permeability values described in both tables confirms that "reduced defect" membrane is formed with PVP as intermediate layer. Table 2 describes the change of selectivity of the above-mentioned gases at different pressure. In case of $\mathrm{H}_{2}$ and $\mathrm{CO}_{2}$, the separation is controlled by competitive adsorption and diffusion. The combined effect of these two determines the ultimate selectivity. 
TABLE 1: Room temperature single gas permeation for $\mathrm{H}_{2}$ and $\mathrm{CO}_{2}$ through SAPO 34 membrane on untreated support at $30^{\circ} \mathrm{C}$.

\begin{tabular}{lcccc}
\hline $\begin{array}{l}\text { Temperature } \\
\left({ }^{\circ} \mathrm{C}\right)\end{array}$ & $\begin{array}{c}\text { Pressure } \\
\left(\mathrm{kg} / \mathrm{cm}^{2}\right)\end{array}$ & $\mathrm{H}_{2}$ & $\mathrm{CO}_{2}$ & Permeance $\times 10^{7}\left(\mathrm{~mol} / \mathrm{m}^{2} \cdot \mathrm{sec}-\mathrm{pa}\right)$ \\
\hline 30 & 2 & 10.23 & 12.0 & 0.85 \\
30 & 3 & 22.5 & 23.2 & 0.96 \\
30 & 4 & 29.5 & 27.5 & 1.07 \\
30 & 5 & 40.1 & 15.0 & 2.67 \\
\hline
\end{tabular}

TABLE 2: Room temperature single-gas permeation for $\mathrm{H}_{2}$ and $\mathrm{CO}_{2}$ through SAPO 34 membrane on the support treated with PVP at $30^{\circ} \mathrm{C}$.

\begin{tabular}{lcccc}
\hline Temperature $\left({ }^{\circ} \mathrm{C}\right)$ & \multicolumn{3}{c}{ Permeance $\times 10^{7}\left(\mathrm{~mol} / \mathrm{m}^{2} \cdot\right.$ sec-pa $)$} & $\mathrm{CO}_{2}$ \\
\hline 30 & Pressure $\left(\mathrm{kg} / \mathrm{cm}^{2}\right)$ & $\mathrm{H}_{2}$ & 1.8 & 3.33 \\
30 & 2 & 6.0 & 6.0 & 1.16 \\
30 & 3 & 7.0 & 4.0 & 4 \\
30 & 4 & 16.0 & 5.0 & 4.2 \\
\hline
\end{tabular}

\section{Conclusion}

SAPO 34 membranes were synthesized on clay alumina tubular support. The membrane in this study was synthesized by ex situ hydrothermal technique. Application of intermediate layer confirms the formation of "reduced defect" SAPO 34 membrane. The intermediate PVP layer helps in formation of uniform seeded layer, which on further treatment forms "reduced defect" membrane. Single gas permeation studies showed that selectivity (permeability ratio) of the permeance increases with increasing feed pressure. The selectivity of the $\mathrm{H}_{2} / \mathrm{CO}_{2}$ slightly increases with increasing pressure. At higher pressure, competitive adsorption and difference in diffusivity due to molecular kinetic diameter are responsible for selectivities of $\mathrm{H}_{2} / \mathrm{CO}_{2}$.

\section{Acknowledgment}

The authors would like to thank CSIR, India, for financial support in the Project no. SIP 0023 and also thankful to Dr. I. Manna Director, CGCRI, for his kind permission to publish the research work.

\section{References}

[1] W. E. Winsche, K. C. Hoffman, and F. J. Salzano, "Hydrogen: its future role in the nation's energy economy," Science, vol. 180, no. 4093, pp. 1325-1332, 1973.

[2] G. J. Stiegel and R. Massood, "Hydrogen from coal gasification: an economical pathway to a sustainable energy future," International Journal of Coal Geology, vol. 65, no. 3-4, pp. 173190, 2006.

[3] C. Koroneos, A. Dompros, G. Roumbas, and N. Moussiopoulos, "Life cycle assessment of hydrogen fuel production processes," International Journal of Hydrogen Energy, vol. 29, no. 14, pp. 1443-1450, 2004.

[4] H. Y. Kim, "A low cost production of hydrogen from carbonaceous wastes," International Journal of Hydrogen Energy, vol. 28, no. 11, pp. 1179-1186, 2003.
[5] M. A. Carreon, S. Li, J. L. Falconer, and R. D. Noble, "Alumina-supported SAPO-34 membranes for CO," Journal of the American Chemical Society, vol. 130, no. 16, pp. 5412-5413, 2008.

[6] M. A. Carreon, S. Li, J. L. Falconer, and R. D. Noble, "SAPO34 seeds and membranes prepared using multiple structure directing agents," Advanced Materials, vol. 20, no. 4, pp. 729732, 2008.

[7] W. Yang, B. Zhang, and X. Liu, "Synthesis and characterization of SAPO- 5 membranes on porous $\alpha$-Al2O3 substrates," Microporous and Mesoporous Materials, vol. 117, no. 1-2, pp. 391-394, 2009.

[8] S. R. Venna and M. A. Carreon, "Amino-functionalised SAPO 34 membranes for $\mathrm{CO}_{2} / \mathrm{CH}_{4}$ and $\mathrm{CO}_{2} / \mathrm{N}_{2}$ separation," Langmuir, vol. 27, pp. 2888-2894, 2011.

[9] Y. Wei, D. Zhang, L. Xu et al., "Synthesis, characterization and catalytic performance of metal-incorporated SAPO-34 for chloromethane transformation to light olefins," Catalysis Today, vol. 131, no. 1-4, pp. 262-269, 2008.

[10] H. Zhou, Y. Wang, F. Wei, D. Wang, and Z. Wang, "Kinetics of the reactions of the light alkenes over SAPO-34," Applied Catalysis A, vol. 348, no. 1, pp. 135-141, 2008.

[11] J. F. M. Denayer, L. I. Devriese, S. Couck et al., "Cage and window effects in the adsorption of n-alkanes on chabazite and SAPO-34," Journal of Physical Chemistry C, vol. 112, no. 42, pp. 16593-16599, 2008.

[12] G. Liu, P. Tian, J. Li, D. Zhang, F. Zhou, and Z. Liu, "Synthesis, characterization and catalytic properties of SAPO34 synthesized using diethylamine as a template," Microporous and Mesoporous Materials, vol. 111, no. 1-3, pp. 143-149, 2008.

[13] Y. Miao, H. H. Funke, R. D. Noble, and J. L. Falconer, " $\mathrm{H}_{2}$ separation using defect-free, inorganic composite membranes," Journal of the American Chemical Society, vol. 133, no. 6, pp. 1748-1750, 2011.

[14] S. Li, J. L. Falconer, and R. D. Noble, "Improved SAPO-34 membranes for CO," Advanced Materials, vol. 18, no. 19, pp. 2601-2603, 2006.

[15] M. Hong, S. Li, J. L. Falconer, and R. D. Noble, "Hydrogen purification using a SAPO-34 membrane," Journal of Membrane Science, vol. 307, no. 2, pp. 277-283, 2008. 
[16] Y. Tian, L. Fan, Z. Wang, S. Qiu, and G. Zhu, "Synthesis of a SAPO-34 membrane on macroporous supports for high permeance separation of a $\mathrm{CO}_{2} / \mathrm{CH}_{4}$ mixture," Journal of Materials Chemistry, vol. 19, no. 41, pp. 7698-7703, 2009.

[17] S. Li and C. Q. Fan, "High-flux SAPO-34 membrane for $\mathrm{CO}_{2} / \mathrm{N}_{2}$ separation," Industrial and Engineering Chemistry Research, vol. 49, no. 9, pp. 4399-4404, 2010.

[18] G. Yang, X. Zhang, S. Liu, K. L. Yeung, and J. Wang, "A novel method for the assembly of nano-zeolite crystals on porous stainless steel microchannel and then zeolite film growth," Journal of Physics and Chemistry of Solids, vol. 68, no. 1, pp. 26-31, 2007.

[19] A. Huang, Y. S. Lin, and W. Yang, "Synthesis and properties of A-type zeolite membranes by secondary growth method with vacuum seeding," Journal of Membrane Science, vol. 245, no. 1-2, pp. 41-51, 2004.

[20] L. C. Boudreau and M. Tsapatsis, "A highly oriented thin film of zeolite A," Chemistry of Materials, vol. 9, pp. 1705-1709, 1997.

[21] M. Tsapatsis, M. Lovallo, T. Okubo, M. E. Davis, and M. Sadakata, "Characterization of zeolite L nanoclusters," Chemistry of Materials, vol. 7, no. 9, pp. 1734-1739, 1995.

[22] M. C. Lovallo and M. Tsapatsis, "Preferentially oriented submicron silicalite membranes," AIChE Journal, vol. 42, no. 11, pp. 3020-3029, 1996.

[23] X. Xu, W. Yang, J. Liu, and L. Lin, "Synthesis and perfection evaluation on NaA zeolite membrane," Separation and Purification Technology, vol. 25, no. 1-3, pp. 475-485, 2001.

[24] S. Y. Choi, Y. J. Lee, Y. S. Park, K. Ha, and K. B. Yoon, "Monolayer assembly of zeolite crystals on glass with fullerene as the covalent linker," Journal of the American Chemical Society, vol. 122, no. 21, pp. 5201-5209, 2000.

[25] A. Kulak, Y. J. Lee, Y. S. Park, and K. B. Yoon, "Orientationcontrolled monolayer assembly of zeolite crystals on glass and mica by covalent linkage of surface-bound epoxide and amine groups," Angewandte Chemie International Edition, vol. 39, no. 5, pp. 950-953, 2000.

[26] G. S. Lee, Y. J. Lee, and K. B. Yoon, "Layer-by-layer assembly of zeolite crystals on glass with polyelectrolytes as ionic linkers," Journal of the American Chemical Society, vol. 123, no. 40, pp. 9769-9779, 2001.

[27] N. Das, D. Kundu, and M. Chatterjee, "The effect of intermediate layer on synthesis and gas permeation properties of $\mathrm{NaA}$ zeolite membrane," Journal of Coatings Technology Research, vol. 7, no. 3, pp. 383-390, 2010. 

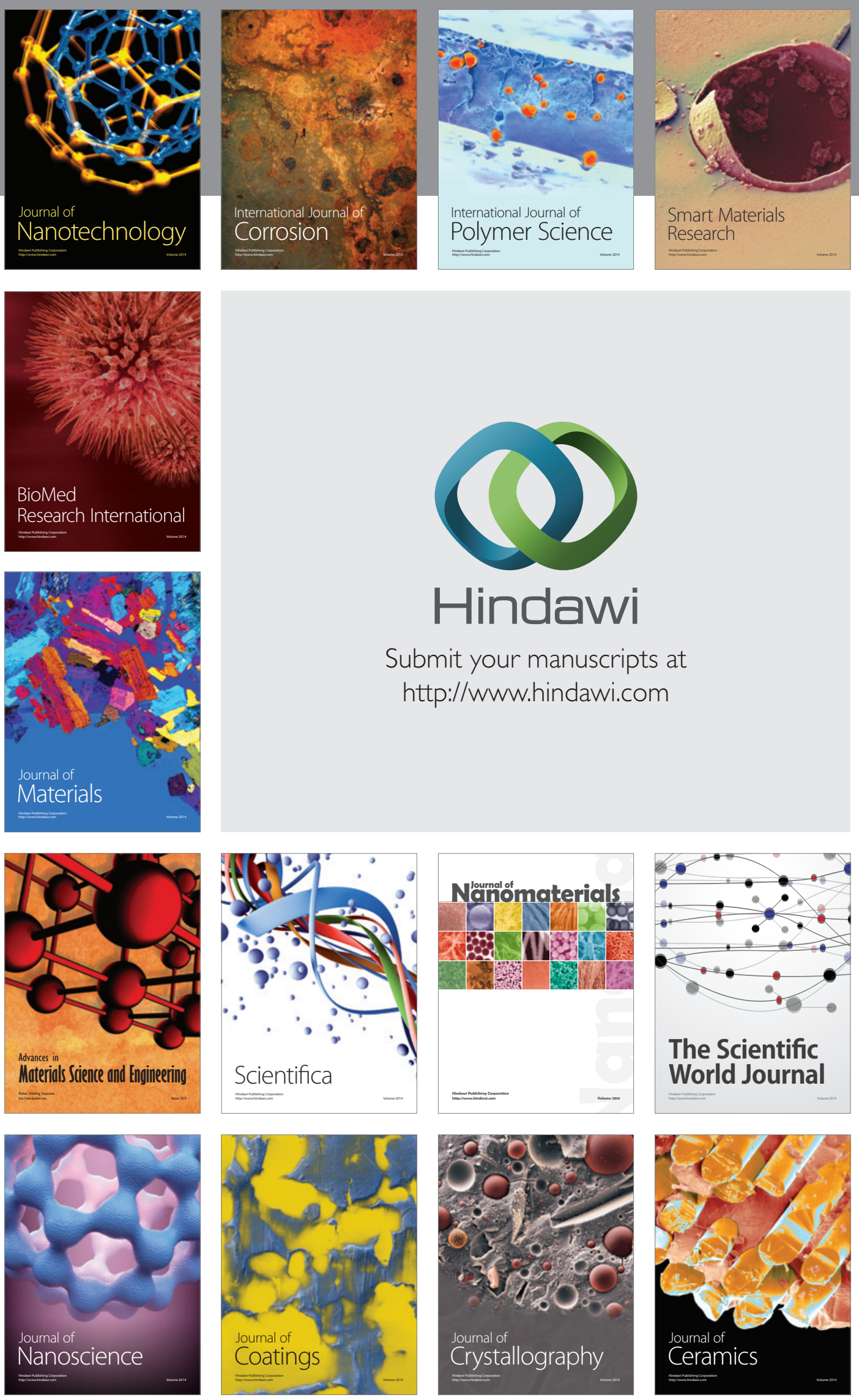

The Scientific World Journal

Submit your manuscripts at

http://www.hindawi.com

\section{World Journal}

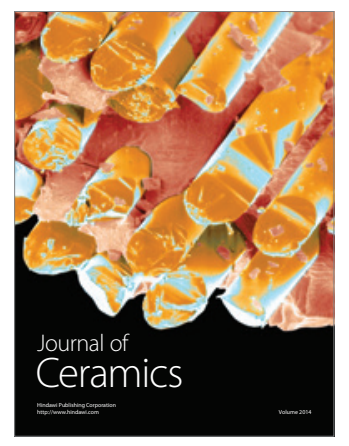

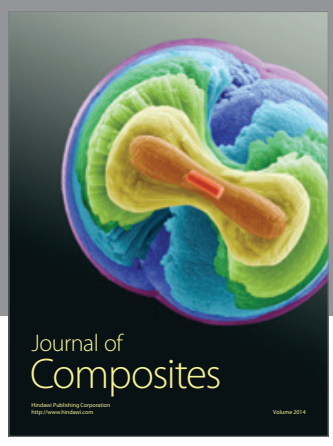
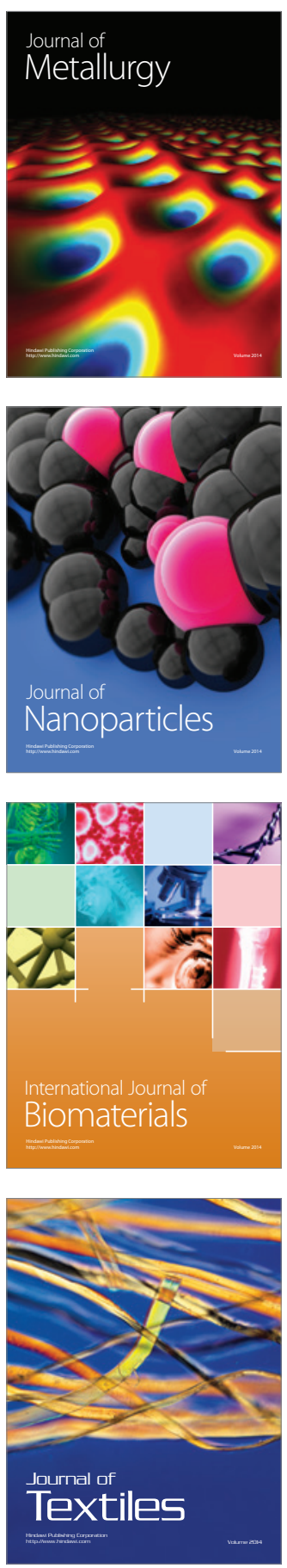